\title{
Androgen Receptor Expression and Bicalutamide Antagonize Androgen Receptor Inhibit $\beta$-Catenin Transcription Complex in Estrogen Receptor-Negative Breast Cancer
}

\author{
Rui Huang ${ }^{a, b, c,}$ Jiguang Han ${ }^{a} \quad$ Xiaoshuan Liang ${ }^{a} \quad$ Shanshan Sun ${ }^{a}$ \\ Yongdong Jiang ${ }^{a}$ Bingshu Xia ${ }^{a}$ Ming Niu ${ }^{a}$ Dalin Li $^{a} \quad$ Jian Zhang ${ }^{a}$ Shuo Wang ${ }^{\mathrm{a}}$ \\ Wei Wei $^{\mathrm{a}}$ Qing Liu ${ }^{\mathrm{a}}$ Wei Zheng ${ }^{\mathrm{a}}$ Guoqiang Zhang ${ }^{\mathrm{a}}$ Yanni Song ${ }^{\mathrm{a}, \mathrm{c}, \mathrm{d}, \mathrm{e}}$ \\ Da Pang a,c,f,g
}

aDepartment of Breast Surgery, Harbin Medical University Cancer Hospital, Harbin, bepartment of General Surgery, The Second Affiliated Hospital of Harbin Medical University, Harbin, cHeilongjiang Academy of Medical Sciences, Harbin, dDepartment of Plastic and Cosmetic Surgery, The First Affiliated Hospital of Harbin Medical University, Harbin, eDepartment of Pathology, Tianjin Medical University Cancer Hospital, Tianjin, ‘Sino-Russian Medical Research Center, Heilongjiang Academy of Medical Sciences, Harbin, ${ }^{9}$ Northern China Translational Medicine Research and Cooperation Center, Heilongjiang Academy of Medical Sciences, Harbin, China

\section{Key Words}

Androgen receptor-positive - Estrogen receptor-negative - Breast cancer - Prognosis • Bicalutamide • Antagonize

\begin{abstract}
Background/Aims: Little is known about the potential mechanism of action for androgen receptor (AR) targeting treatment in estrogen receptor (ER)-negative breast cancer. This study aimed to evaluate AR status and its prognosis in four breast cancer subtypes. Bicalutamide has been identified as an AR antagonist and used for treating AR+/ER- breast cancer in a phase II trial. Our studies will clarify its mechanism in breast cancer treatment. Methods: A total of 510 consecutive cases of invasive ductal cancer (IDC) were evaluated in this study. The expression of AR was analyzed by immunohistochemistry and compared with patient survival, and its implications were evaluated in four subtypes of IDC. We examined bicalutamide as an AR antagonist to inhibit proliferation and increased apoptosis in AR+/ER- breast cancer cell lines. We explored the tumor suppressive functions of bicalutamide in vitro and vivo and its related mechanisms in AR+/ER- breast cancer. Results: AR expression was related to that of ER $(P<0.001)$, PR $(P<0.001)$, Her2 $(P=0.017)$, Ki-67 $(P=0.020)$ and to four subtypes $(P<0.001)$.

R. Huang and J. Han are contributed equally to this work.

Yanni Song

and Da Pang,

Harbin Medical University Cancer Hospital Department of breast surgery;

Heilongjiang Institute for Cancer Research, 150 Haping Road, Nangang District, Harbin 150081, (China); E-Mail yannimd@126.com, pangdasir@163.com
\end{abstract}

KARGER 


\section{Cellular Physiology Cell Physiol Biochem 2017;43:2212-2225

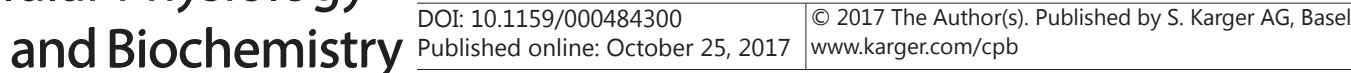 \\ Huang et al.: AR Expression and Bic Antagonize AR Inhibit $\beta$-Catenin in ER- Breast \\ Cancer}

AR retained independent prognostic significance ( $P=0.007$, ER- cases; $P=0.001$, ER+ cases; $P=0.001$, total cases). We found that bicalutamide significantly decreased viability and increased apoptosis in vitro and vivo. The mechanistic analysis revealed that bicalutamide blocked androgen-stimulated oncogenic AR and Wnt/ $\beta$-catenin signaling and inhibited the growth of $A R+/ E R$ - breast cancer. Conclusion: Our studies provide novel insights into bicalutamide as an antagonist of $A R$ function in AR+/ER- breast cancer and reveal the mechanistic basis for targeting $A R$ as a therapeutic opportunity for patients with $A R+/ E R$ - breast cancer.

(C) 2017 The Author(s)

Published by S. Karger AG, Basel

\section{Introduction}

Androgen receptor (AR) is expressed frequently and is widespread in breast cancer, and breast cancer tissue has the third highest expression of AR among various tissues [1](Fig. 1). Currently, it is indicated that AR and AR inhibition play an important role in patients with breast cancer $[2,3]$. AR is typically expressed in a greater proportion of breast cancers $(80-$ 90\%) than the estrogen receptor (ER) (50-80\%) [4], and previous studies have suggested the potential for AR to predict disease progression [5, 6] and provide a target for therapy [3, 7]. Studies of estrogen and ER have led to significant progress in the development of endocrine therapies targeting estrogen production or ER, contributing to both breast cancer prevention and treatment $[8,9]$. Despite androgen and AR being widely recognized for their expression in breast cancer, little is known concerning a potential mechanism of action for the targeted treatment of this disease. Molecular expression profiling has been used to classify breast cancer into four subtypes, luminal A, luminal B, triple negative breast cancer (TNBC, ER-/ PR-/Her2-) and human epidermal growth factor receptor 2 (Her2) over expressing(ER-/ PR-/Her2+), according to the St. Gallen International Expert Consensus 2013 [10, 11]. ER and Her2 serve as prognostic markers and direct therapeutic targets (hormonotherapy and trastuzumab, respectively) for the luminal A, luminal B and Her2-overexpressing subtypes. Patients with breast cancer that lacks expression of the ER and progesterone receptor (PR) have not traditionally derived any benefit from conventional endocrine therapies such as selective ER modulators or aromatase inhibitors. AR expression varies across the clinical subtypes: approximately 80-95\% in ER+ tumors [12], 30-65\% in ER-/Her2+ tumors [13, 14], and $10-50 \%$ in TNBC $[10,12,14,15]$. However, despite the high frequency of AR expression in breast cancer, it is still not standard clinical practice to use AR antagonists as therapy, though it has been used in clinical trials (NCT00468715 and NCT01889238) $[16,17]$.

$\mathrm{AR}$ is a ligand-dependent transcription factor that controls the expression of specific genes involved in the onset of breast cancer [18]. For targeting AR, bicalutamide has been used clinically as an anti-androgen. Bicalutamide, an oral, non-steroidal anti-androgen that competitively inhibits the binding of androgens to AR, has provided a proof of principle for the efficacy of minimally toxic androgen inhibition in a select group of patients with AR+/ ER-/PR- breast cancer. AR antagonists may have a particularly in AR+/ER- (AR positive and ER negative) breast cancers, including the TNBC and Her2-overexpressing subtypes. In the absence of ER, the role of AR and anti-androgen signaling in regulating cell proliferation has been a little clearer.

Khramtsov and colleagues [19] reported that Wnt/ $\beta$-catenin activation is an important feature of TNBC and predictive of worse overall survival. Moreover, these strong data suggested that Wnt/ $\beta$-catenin pathway activation is implicated in mouse models of breast cancer [20]. Chesire [21] studied the interaction between $\beta$-catenin and AR in several cell lines, including kidney epithelial cells and human breast cancer cells and demonstrated that $\beta$-catenin enhanced AR-dependent transcription by directly interacting with this receptor. A recently concluded clinical trial (NCT00468715) of bicalutamide in patients with metastatic $\mathrm{AR}+$ /ER- breast cancer reported a modest clinical benefit rate of $20 \%$. The underlying mechanisms and signaling pathways are poorly understood. We hypothesized that AR+/ERbreast cancer might also critically depend on the AR and $\beta$-catenin transcription complex and may benefit from treatment with bicalutamide. Our study detected the expression of 


\section{Cellular Physiology Cell Physiol Biochem 2017;43:2212-2225 \begin{tabular}{l|l|l} 
DOI: 10.1159/000484300 & $\begin{array}{l}\text { O 2017 The Author(s). Published by S. Karger AG, Basel } \\
\text { www.karger.com/cpb }\end{array}$
\end{tabular} \\ Huang et al.: AR Expression and Bic Antagonize AR Inhibit $\beta$-Catenin in ER- Breast Cancer}

AR by immunohistochemistry (IHC) in four breast cancer subtypes. In this study, we show that AR level is significantly associated with disease outcome and indicate the biological functions of bicalutamide in AR+/ER- subtype breast cancer cells in vivo and vitro.

\section{Materials and Methods}

Patient characteristics and analysis of clinicopathological parameters

A total of 510 consecutive cases of invasive ductal (IDC) breast cancer were collected in this study, with a mean age of 50.5 years, who underwent mastectomy at Harbin Medical University Cancer Hospital (HMUCH) from January 2006 to December 2007. The patient's medical and follow-up data were retrieved from the hospital records and interviews. The following information was extracted from them: histopathology and treatment characteristics, such as tumor size, histological grade, hormone receptor status and lymph node involvement. The tumor grade and stage were classified according to the 7th edition of the AJCC staging system [22]. All patients were treated according to modern guidelines, including the use of adjuvant chemotherapy for IDC breast cancer and endocrine therapy for ER+/PR+ subtypes. No patient received any therapy before surgery. Ethical approval for the study was obtained through the Heilongjiang Regional Ethics Committee. Informed consent was obtained from all patients before surgery and examination of the specimens.

\section{Immunohistochemical assay and evaluation of staining}

Breast cancer tissue microarrays (TMA) were used as described previously [23, 24] and immunohistochemically stained for AR, ER, PR, Her2, Ki67 and $\beta$-catenin expression levels. Briefly, after deparaffinization, sections were hydrated and underwent Ethylene Diamine Tetraacetic Acid (EDTA) buffer (pH 8.0) or sodium citrate buffer ( $\mathrm{pH} \mathrm{6.0)} \mathrm{retrieval.} \mathrm{The} \mathrm{slides} \mathrm{were} \mathrm{treated} \mathrm{with} \mathrm{methanol} \mathrm{containing}$ $0.3 \%$ hydrogen peroxide to block any endogenous peroxidase activity. Heat-mediated antigen retrieval with a pressure cooker method was used for all staining. A rabbit polyclonal antibody to the AR antibody (ab74272; 1:100dilution; Abcam) was used to evaluate AR protein expression level. The primary antibodies used in this study included ER (ab180900; 1:200dilution; Abcam), PR (ab63605; 1:300dilution; Abcam), Her2 (ab16901; 1:200dilution; Abcam), Ki67 (ab66155; 1:150dilution; Abcam), and $\beta$-catenin (ab32572; 1:400dilution; Abcam). For each antibody, the location of immunoreactivity, percentage of stained cells and intensity were determined. The evaluation of each protein's expression was determined from the mean of the individual cases. AR, ER, PR and Ki67 stains were assessed using Allred scores [25]. Her2+ was defined as strong membrane staining in $>10 \%$ of the tumor cells. Tumors with a $>2.2$-fold increase in Her2 gene amplification, as determined by fluorescence in situ hybridization (FISH), were considered to be positive for Her2 overexpression [26]. Immunostaining was scored by two pathologists who were blinded to the patient's clinicopathological characteristics and outcomes. The analysis of breast cancer subtypes has been described previously $[10,11]$ and was based on the gene expression patterns. The subtype definitions were as follows: luminal A (ER+ and/or PR+ and Her2- and Ki67<14\%), luminal B (ER+ and/or PR+ and Her2and Ki67>14\%; ER+ and/or PR+ and Her2+ and Ki67 anyway), Her2 overexpression (ER-, PR- and Her2+), TNBC (ER-, PR- and Her2-). To eliminate nonspecific staining, a negative control was performed with PBS.

\section{Cell culture}

MDA-MB-231 (MB-231) and MDA-MB-453 (MB-453) cells were purchased from the American Tissue Culture Collection (ATCC). MB-231 (TNBC) and MB-453 (Her2 overexpression) were chosen because two represents cell lines express moderate and high levels of AR in the absence of ER and PR breast cancer [7, 13, 27-29]. LnCap cell lysates, used as a positive control for AR, were a present from Dr Yongsheng Chen (Harbin Medical University). All cell lines were maintained at $37^{\circ} \mathrm{C}$ in RPMI 1640 medium supplemented with $10 \%$ Fetal Bovine Serum (FBS) (Invitrogen, CA, USA), 1\% penicillin/streptomycin, L-glutamine, nonessential amino acids, and insulin supplementation. Cell line identity was confirmed by analysis of short-term repeat loci and cells were routinely tested for mycoplasma infection. MB-231 and MB-453 cell with either AR or $\beta$-catenin knockdown cells were generated by lentiviral transduction of shRNAs targeting AR and $\beta$-catenin (Invitrogen, CA, USA) 


\section{Cellular Physiology Cell Physiol Biochem 2017;43:2212-2225 \begin{tabular}{l|l|l} 
and Biochemistry & $\begin{array}{l}\text { DOI: 10.1159/000484300 } 2017 \text { The Author(s). Published by S. Karger AG, Basel } \\
\text { Published online: October 25, } 2017\end{array}$ & \begin{tabular}{l} 
ww.karger.com/cpb \\
\hline
\end{tabular}
\end{tabular}}

Huang et al.: AR Expression and Bic Antagonize AR Inhibit $\beta$-Catenin in ER- Breast Cancer

\section{Cellular assays and reagents}

MB-231 and MB-453 cells were treated with $10 \mathrm{nmol} / \mathrm{L}$ Dihydrotestosterone (DHT) (SigmaAldrich), $10 \mathrm{mmol} / \mathrm{L}$ bicalutamide (AstraZeneca, Germany). A concentration of $10 \mathrm{mmol} / \mathrm{L}$ bicalutamide approximates the $\mathrm{IC}_{50}$ for the two cell lines studied $[3,13]$ and is a clinically achievable concentration. Androgen concentrations have been previously examined in breast cancer [13,30]. The DHT levels in the FBS used during routine tissue culture propagation were monitored [31]. Colony formation assays were performed using monolayer culture. Cells (MB-231 and MB-453) were plated in six-well plates and treated with DHT and bicalutamide or transfected with shRNA-AR or shRNA- $\beta$-catenin plasmids (Invitrogen, CA, USA). Plating efficiency was calculated by dividing the number of colonies by the original seeding density. The surviving fraction was determined by comparing the plating efficiency of the treated wells to that of the control wells. Surviving colonies were counted after staining with Gentian Violet. All experiments were performed three times.

\section{In situ hybridization}

Terminal deoxynucleotidyl transferase-mediated dUTP nick-end labeling (TUNEL) staining for apoptosis was performed using the ApopTag Plus Peroxidase In Situ Apoptosis Detection kit (Invitrogen, CA, USA), per the manufacturer's instructions.

\section{Real-time quantitative PCR}

RNA was isolated from cell lines using TRIzol Reagent (Invitrogen, Beijing, China), RNA quality and concentration were measured using a GeneQuant pro (GE Healthcare, Piscataway, NJ, USA), and cDNA was synthesized from $1 \mu \mathrm{g}$ total RNA, using M-Mulv reverse transcriptase enzyme (Takara Bio, Otsu, Japan). qPCR was performed using the ABI 7500 Fast Sequence Detection System (Applied Biosystems, Foster City, CA, USA). SYBR green quantitative gene expression analysis was performed using the following primers: AR forward, 5'-GAACCACAAATACCTGGCTA-3'and AR reverse, $5^{\prime}$-TCCATTTTTGCCTCCCTTTT- $3^{\prime}$; $\beta$-catenin forward, $5^{\prime}$-GAGGAGAA-GAGGAAAGAGA-3'and $\beta$-catenin reverse, $5^{\prime}$-TTGAGGACCTC-TGTGTATTTG-3'; $\beta$-ACTIN forward, $5^{\prime}$-CCTGTGGCATCCACGAAACT- $3^{\prime}$ and $\beta$-ACTIN reverse, $5^{\prime}$-GAAGCATTTGCGGTGGACGAT- $3^{\prime}$. Relative gene expression was calculated using the comparative cycle threshold method and values were normalized to $\beta$-actin, AR and $\beta$-catenin.

\section{Cellular fractionation}

Cellular fractionation was performed using the NE-PER Nuclear and Cytoplasmic Extraction Kit (Sigma Aldrich) as per the manufacturer's instructions.

\section{Western blot}

Total proteins were quantified using the Pierce BCA Protein Assay Kit (Bio-Rad, Hercules, CA, USA), and $50 \mu \mathrm{g}$ of protein per sample was separated onto a denaturing sodium dodecyl sulfate polyacrylamide gel containing SDS-PAGE, and then transferred to a methanol-activated PVDF filter membrane (Thermo Scientific, Rockford, IL, USA). The lysates were then transferred to PVDF membranes for antibody incubation. After blocking with $5 \%$ nonfat milk and $0.1 \%$ Tween 20 in TBS, the membranes were incubated with anti-AR (ab74272; 1:1000 dilution; ABcam) or $\beta$-catenin antibody (ab180900; 1:1200 dilution; ABcam), CMYC (ABcam, Burlingame, CA) at $4{ }^{\circ} \mathrm{C}$ overnight.. After subsequent washing with TBST, membranes were incubated with secondary antibody for $1 \mathrm{~h}$ at room temperature. GAPDH was used as a control. The bands were detected by enhanced chemiluminescence detection reagents (Applygen Technologies, Beijing, China).

\section{Xenografted tumor model}

Xenograft experiments were approved by the Animal Feeding Center of Harbin Medical University Cancer Hospital and Use Committee (HMUCH protocol). All animal experiments were conducted in accordance with the NIH Guidelines of Care and Use of Laboratory Animals. A total of $5 \times 10^{5} \mathrm{MB}-231$ or $1 \times 10^{6} \mathrm{MB}-453$ cells were mixed with Matrigel (BD Biosciences) and injected into the mammary fat pads of female BALB/c nude mice (Weitong Lihua Experimental Animal Technology Co., Ltd, Beijing). Tumor burden was assessed by caliper measurements [tumor volume was calculated as volume $=\left(\right.$ length $\times$ width $\left.^{2}\right) / 2$ ] . Once tumors were established, the mice were randomized into groups based on the total tumor burden as measured by Vernier calipers. Mice were administered bicalutamide in their chow (10 mg/kg daily dose) [13]. The feed was irradiated and stored at $4^{\circ} \mathrm{C}$ before use. Bicalutamide was mixed with ground mouse

\section{KARGER}


Huang et al.: AR Expression and Bic Antagonize AR Inhibit $\beta$-Catenin in ER- Breast Cancer

chow (Research Diets Inc.) at $0.2 \mathrm{mg} / \mathrm{g}$ chow. Mice in the control group received the same ground mouse chow but without bicalutamide. All mice were given free access to bicalutamide formulated chow or control chow during the study period. Mice were euthanized by carbon dioxide asphyxiation followed by cervical dislocation, and the tumors and mammary glands were harvested.

\section{Statistical analysis}

Statistical analyses were performed with SPSS version 16.0 statistical software. Statistical analysis of the data was performed with paired Student's t-test or one-way ANOVA for differences between experimental group mean values. Overall survival (OS) time was calculated from the date of the first definite operation to the date of the last follow-up, or death from any cause. OS curves were generated according to the KaplanMeier method. Multivariate analysis was carried out with Cox regression analysis. For all the tests, $P<0.05$ was considered as statistical significance.

\section{Results}

AR expression in breast cancer is related to OS in different subtypes

To assess the expression and prognostic value of AR expression in four molecular subtypes of breast cancer, we conducted immunohistochemical analysis of AR in a cohort of 510 IDC lesions. Among the 510 patients with follow-up data, a large percentage $(79.0 \%)$ $(403 / 510)$ of patients displayed nuclear immunoreactivity for AR, and AR expression was found in 76\% (60/79) of Her2 overexpression patients and 39\% (36/93) of the triple-negative (TN) subtype patients. AR expression was related to pathological node stage $(P=0.040)$, ER $(P<0.001)$, PR $(P<0.001)$, Her2 $(P=0.017)$, Ki-67 $(P=0.020)$, subtype $(P<0.001)$ and hormone therapy $(P<0.001)$ but showed no relation to other parameters, such as age, menopause status, tumor size, clinical stage, histological grade, operation or chemotherapy in the treated cohort (Table 1). IHC staining of each protein marker and AR expression in the four subtypes of breast cancer tissues is illustrated in Fig. 2. The expression of AR was significantly associated with improved survival. Fig. 3A shows the 5 Year-OS $(P=0.007)$ curve of 236 ER-negative patients with AR-positive and AR-negative breast cancer. Fig. 3B shows the 5 Year-OS $(P=0.001)$ curve of 274 ER-positive patients with AR-positive and AR-negative breast cancer. Fig. $3 \mathrm{C}$ shows the 5 Year-OS $(P=0.001)$ curve of 510 patients with AR-positive and AR-negative breast cancer. In 510 breast cancer patients, multivariate Cox regression analysis indicated a 2.36-fold increase in the risk of cancer-related death (5 Year-OS) $(P=0.023)$ for AR-negative patients compared with AR-positive patients (Fig. 3D).

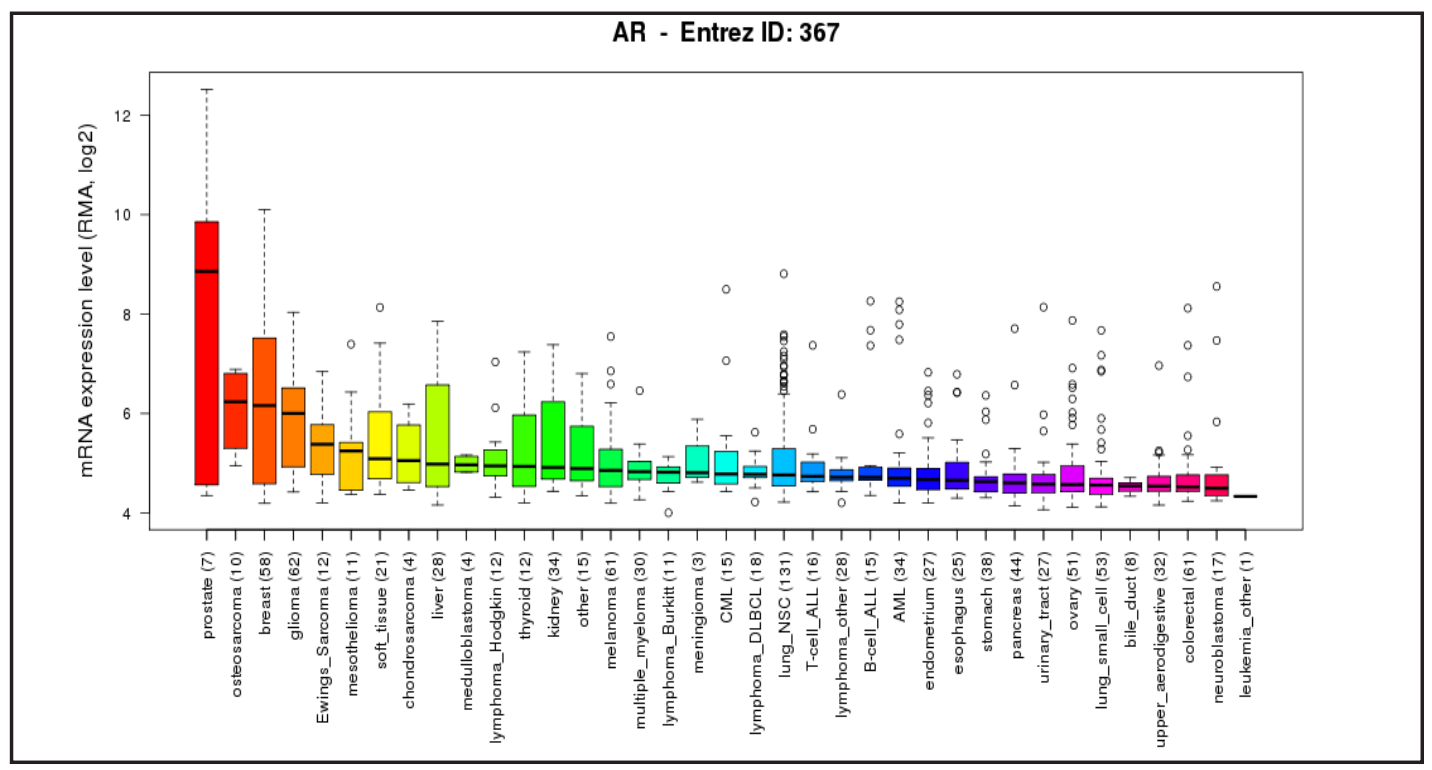

Fig. 1. Gene Expression data for AR extracted from Cancer Cell Line Encyclopedia (CCLE).The breast cancer tissue has the third highest expression of AR among various tissues. 
Huang et al.: AR Expression and Bic Antagonize AR Inhibit $\beta$-Catenin in ER- Breast Cancer

Bicalutamide decreases proliferation and increases apoptosis in ER-negative breast cancer cells

AR inhibition was studied in MB-453 andMB-231 cell lines, which both represent ERnegative breast cancer cells. Using crystal violet staining, DHT was observed to increase the proliferation of the MB-453 and MB-231 cell lines, and bicalutamide significantly decreased ligand-mediated and baseline proliferation inserum (Fig. 4A, $\left.{ }^{* *} P<0.001\right)$. The MTT assay was used to examine the effect of combination treatment with DHT and bicalutamide, which resulted in a more significant suppressive effect on cell proliferation at 72 hours (Fig. 4B, ${ }^{* *} P<0.001$ ). Colony formation assays were performed to assess the effect of bicalutamide on cell proliferation in breast cancer. An approximate $70-80 \%$ reduction in colony numbers was observed in MB-453 and MB-231 cells compared with the vehicle control (Veh) (Fig. 4C, $* * P<0.001$ ), suggesting that bicalutamide decreases growth and may decrease tumorigenicity in vitro. Bicalutamide also increased apoptosis and caspase- $3 / 7$ activity compared with the vehicle control in MB-453 and MB-231 cells (Fig. 4D, ${ }^{* *} P<0.001$ ).

\section{Bicalutamide inhibits ER- negative breast tumor growth in vivo}

To determine the antitumor effect of targeting AR in vivo, we established MB-453 and MB231 xenograft models. The MB453 and MB-231 cells were implanted in the mammary gland of BALB/c nude mice, and one group of the mice received the concomitant implantation of a DHT slow-release pellet. DHT dramatically promoted the
Table 1. AR expression of breast cancer in relation to clinical and pathological features; BCS: breast conservative surgery. MRM: modified radical mastectomy

\begin{tabular}{|c|c|c|c|c|}
\hline \multirow[b]{2}{*}{ Factor } & \multirow[b]{2}{*}{$\mathrm{N}$} & \multicolumn{3}{|c|}{ No. of AR $(n=510)$} \\
\hline & & AR $(-)$ & $\mathrm{AR}(+)$ & $\mathrm{P}$ \\
\hline Age & & & & .062 \\
\hline$<50$ & 279 & $51(18 \%)$ & 228 (82\%) & \\
\hline$\geq 50$ & 231 & $56(24 \%)$ & 175 (76\%) & \\
\hline Menopause status & & & & .129 \\
\hline Premenopausal & 275 & $52(19 \%)$ & 223 (81\%) & \\
\hline Postmenopausa & 235 & $55(23 \%)$ & $180(77 \%)$ & \\
\hline Pathological T stage & & & & .192 \\
\hline $\mathrm{T} 1(\leq 2 \mathrm{~cm})$ & 173 & $32(18 \%)$ & $141(82 \%)$ & \\
\hline $\mathrm{T} 2-4(>2 \mathrm{~cm})$ & 337 & 75 (22\%) & $262(78 \%)$ & \\
\hline Pathological N stage & & & & .040 \\
\hline NO & 231 & 57 (25\%) & $174(75 \%)$ & \\
\hline N1-3 & 279 & $50(18 \%)$ & 229 (82\%) & \\
\hline Clinical stage & & & & .217 \\
\hline Stage I & 102 & $18(18 \%)$ & $84(82 \%)$ & \\
\hline Stage II-III & 408 & $89(22 \%)$ & $319(78 \%)$ & \\
\hline Histological grade & & & & .083 \\
\hline G1 & 54 & $7(13 \%)$ & 47 (87\%) & \\
\hline G2-3 & 456 & $100(22 \%)$ & $356(78 \%)$ & \\
\hline ER & & & & $<.001$ \\
\hline ER $(-)$ & 274 & 94 (34\%) & $180(66 \%)$ & \\
\hline ER (+) & 236 & $13(6 \%)$ & $223(94 \%)$ & \\
\hline $\mathrm{PR}$ & & & & $<.001$ \\
\hline PR (-) & 204 & 79 (39\%) & 125 (61\%) & \\
\hline PR (+) & 306 & $28(9 \%)$ & $278(91 \%)$ & \\
\hline Her2 & & & & .017 \\
\hline Her2 $(-)$ & 399 & $92(23 \%)$ & 307 (77\%) & \\
\hline Her2 $(+)$ & 111 & $15(14 \%)$ & 96 (86\%) & \\
\hline $\mathrm{Ki}-67$ & & & & .020 \\
\hline Ki- $67<14 \%$ & 276 & $48(17 \%)$ & $228(83 \%)$ & \\
\hline $\mathrm{Ki}-67 \geq 14 \%$ & 234 & $59(25 \%)$ & $175(75 \%)$ & \\
\hline Subtype & & & & $<.001$ \\
\hline Luminal A & 123 & $14(8 \%)$ & 169 (92\%) & \\
\hline Luminal B & 155 & $17(11 \%)$ & $138(89 \%)$ & \\
\hline Her2 (+) & 79 & $19(24 \%)$ & $60(76 \%)$ & \\
\hline Tripple negative & 93 & $57(61 \%)$ & 36 (39\%) & \\
\hline Operation & & & & .148 \\
\hline BCS & 127 & $22(17 \%)$ & 105 (83\%) & \\
\hline MRM & 383 & 85 (22\%) & 298 (78\%) & \\
\hline Chemotherapy & & & & .519 \\
\hline Yes & 373 & 78 (21\%) & 295 (79\%) & \\
\hline No & 137 & $29(21 \%)$ & $108(79 \%)$ & \\
\hline Hormone therapy & & & & $<.001$ \\
\hline Yes & 271 & 30 (11\%) & 241 (89\%) & \\
\hline No & 239 & $77(32 \%)$ & $162(68 \%)$ & \\
\hline
\end{tabular}

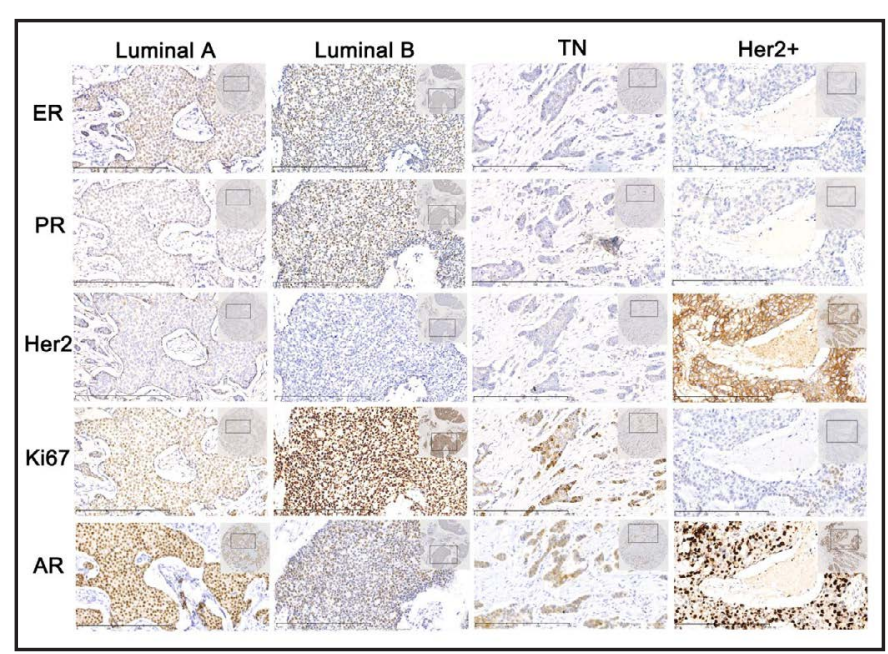

Fig. 2. Expression of ER, PR, Her2, Ki67 and AR by Immunohistochemical staining in Luminal A, Luminal B, TN and Her2+ breast cancer (the same patient with the same lesion site of each type). Positive expression of ER, PR, Ki67 and AR revealed nuclear staining, original magnification $\times 50$ and $\times 200$. Positive expression of Her 2 revealed membrane staining, original magnification $\times 50$ and $\times 200$. 
Huang et al.: AR Expression and Bic Antagonize AR Inhibit $\beta$-Catenin in ER- Breast Cancer

Fig. 3. Survival curves according to androgen receptor (AR) expression stratified by estrogen receptor (ER) status. (A) Kaplan-Meier analysis for 5-Year overall survival (OS) in patients with ERnegative tumor. (B) Kaplan-Meier analysis for 5-Year OS in patients with ER-positive tumor. (C) Kaplan-Meier analysis for 5-Year OS in total patients. (D) Cox regression model multivariate analysis for 5-Year OS in total patients.

Fig. 4. Bicalutamide decreases proliferation and increases apoptosis in Her2 overexpression and TNBC cell lines. (A) Crystal violet assay of MB-453 and MB-231 treated with vehicle control (Veh), bicalutamide (Bic), and/or DHT. (B) MTT assay was used to measure MB-453 and MB-231 cell proliferation. (C) Soft agar assays of MB-453 and MB-231 cell lines treated with Veh or Bic in full serum. (D) Apoptotic index of nuclear red MB-453 and MB-231 cell lines treated with Veh (solid circle) or Bic (solid square). **, $\mathrm{P}<0.01$.
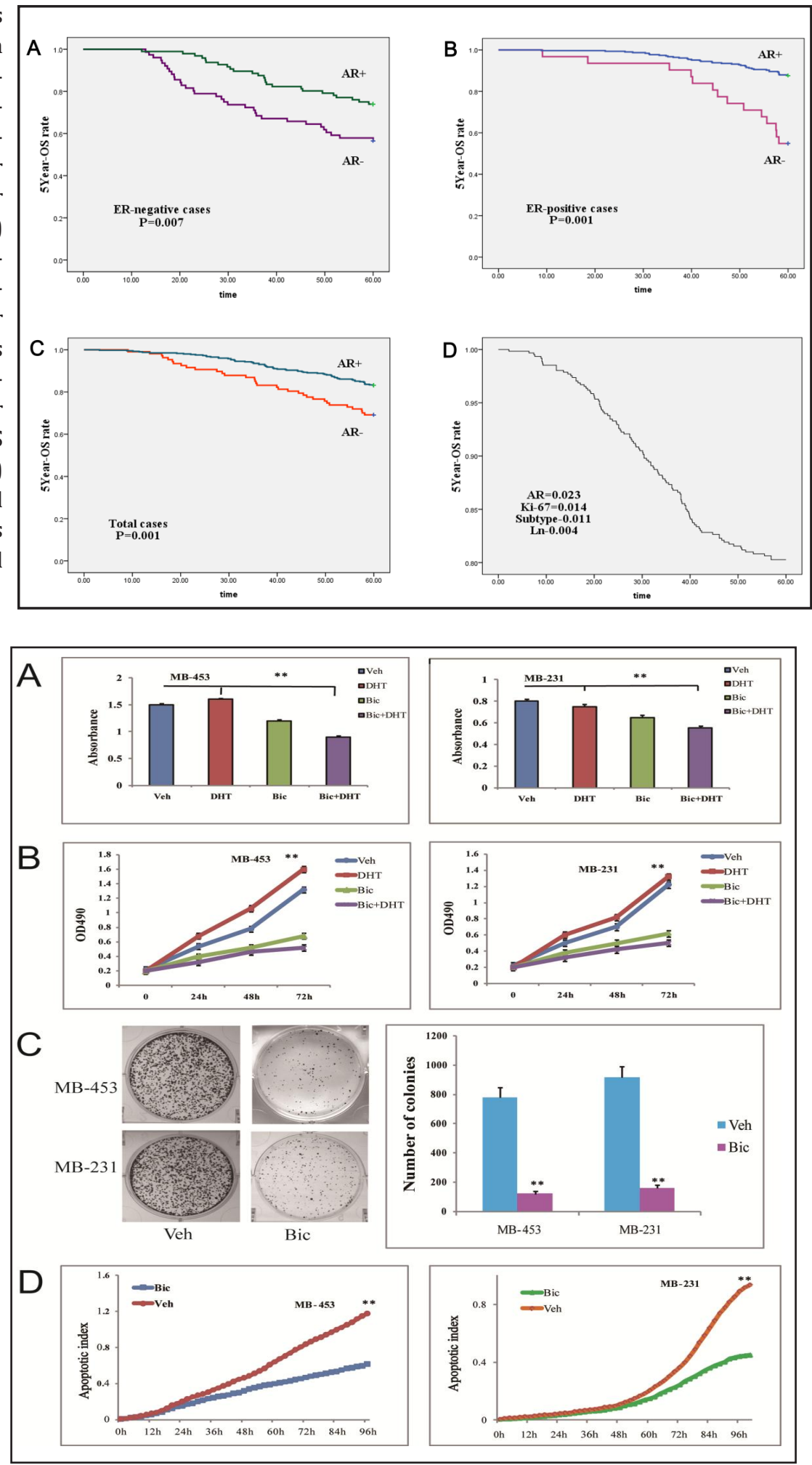

growth of MB-453 tumors. After tumors reached a volume of $500 \mathrm{~mm}^{3}$, daily oral administration of bicalutamide at $10 \mathrm{mg} / \mathrm{kg}$ was delivered to $50 \%$ of the mice carrying DHT pellets $(\mathrm{n}=3)$. As expected bicalutamide treatment resulted in a significant inhibition of the DHTstimulated growth of MB-453 and MB-231 xenograft tumors ( $\left.{ }^{*} P<0.001\right)$, and tumors re- 


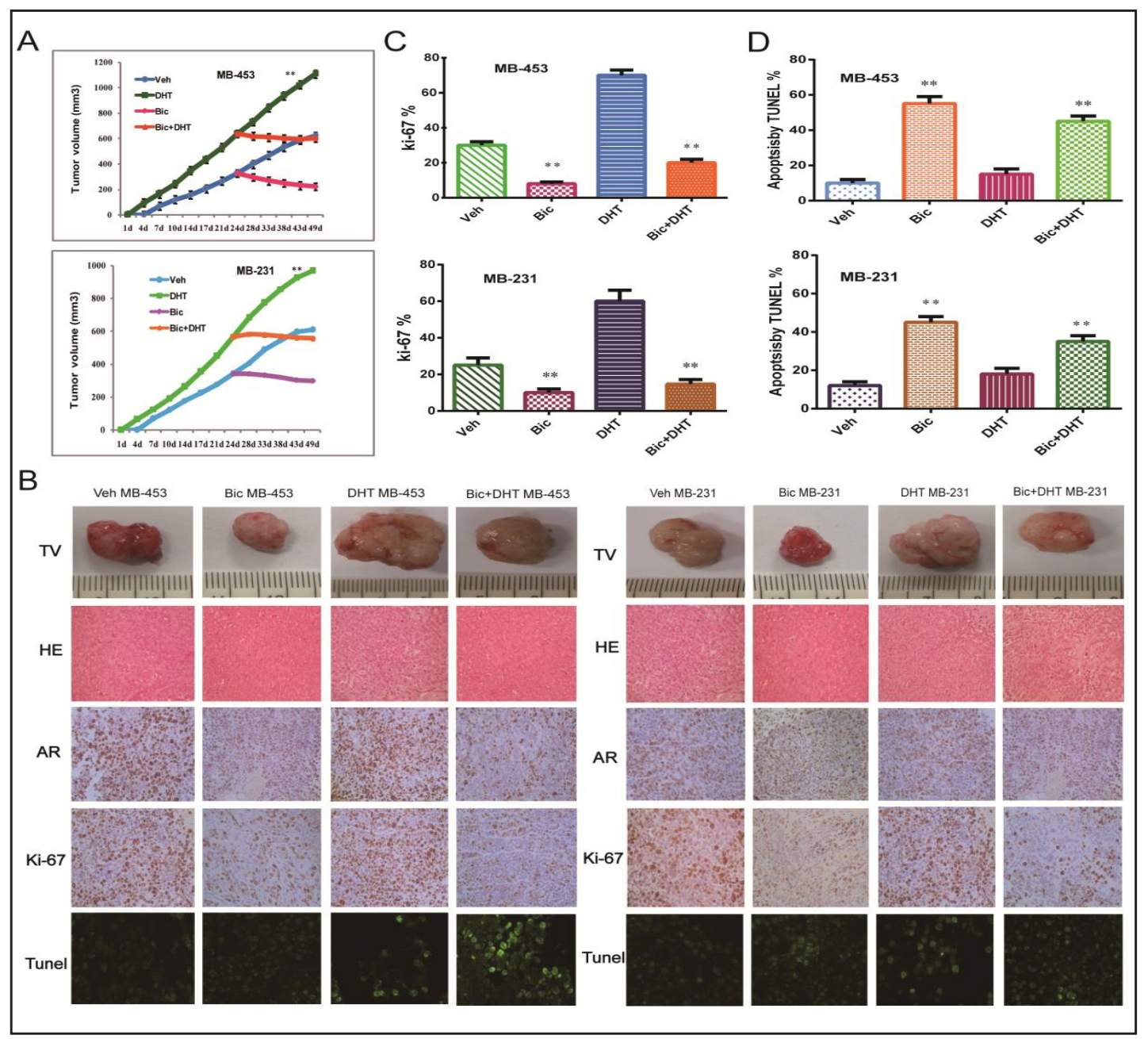

Fig. 5. Bicalutamide (Bic) decreases cellular viability and increases necrosis and apoptosis in MB-453 and MB-231 xenografts. (A) Effects of vehicle control (Veh), Bic, and/or DHT on the growth of xenograft tumors. MB-453 and MB-231 cells were orthotopically implanted in the fourth inguinal gland of SCID mice. (B) Solid tumor, immunohistochemisty (IHC) and Tunel staining of MDA-MB-453 xenograft tumors from different treatment groups to examine the expression. (C) Ki67 proteins expression of Veh, Bic, and/or DHT by IHC. (D) Tunel analysis for apoptosis from different treatment groups.

gressed to control levels after 4 weeks of treatment (Fig. 5A). Representative images from the analyzed tumor sections and the subcutaneous tumors are shown in Fig. 5B. IHC was performed to analyze the expression of the cell proliferation marker Ki-67 in xenograft tumors. In hematoxylin and eosin (H\&E)-stained sections from xenograft tumors of MB-453 and MB-231 cells without bicalutamide treatment, numerous tumor cells with positive Ki-67 expression were observed compared to cells with bicalutamide treatment (Fig. 5C, $\left.{ }^{* *} P<0.001\right)$. These results indicate that bicalutamide acts as a tumor suppressor in breast tumorigenesis. Bicalutamide treatment enhanced cell death compared to xenograft tumors without treatment, as detected by the Tunel assay (Fig. 5D, ${ }^{*} P<0.001$ ).

\section{Bicalutamide inhibits AR cooperates with $\beta$-catenin in transcriptional downregulation of CMYC}

The molecular mechanism of how bicalutamide influences the development of AR is unclear. As shown in Fig. 6A, we explored the different interaction partners of AR using Ingenuity Pathway Analysis (IPA) software (String Database). The analysis speculated 
Huang et al.: AR Expression and Bic Antagonize AR Inhibit $\beta$-Catenin in ER-Breast Cancer

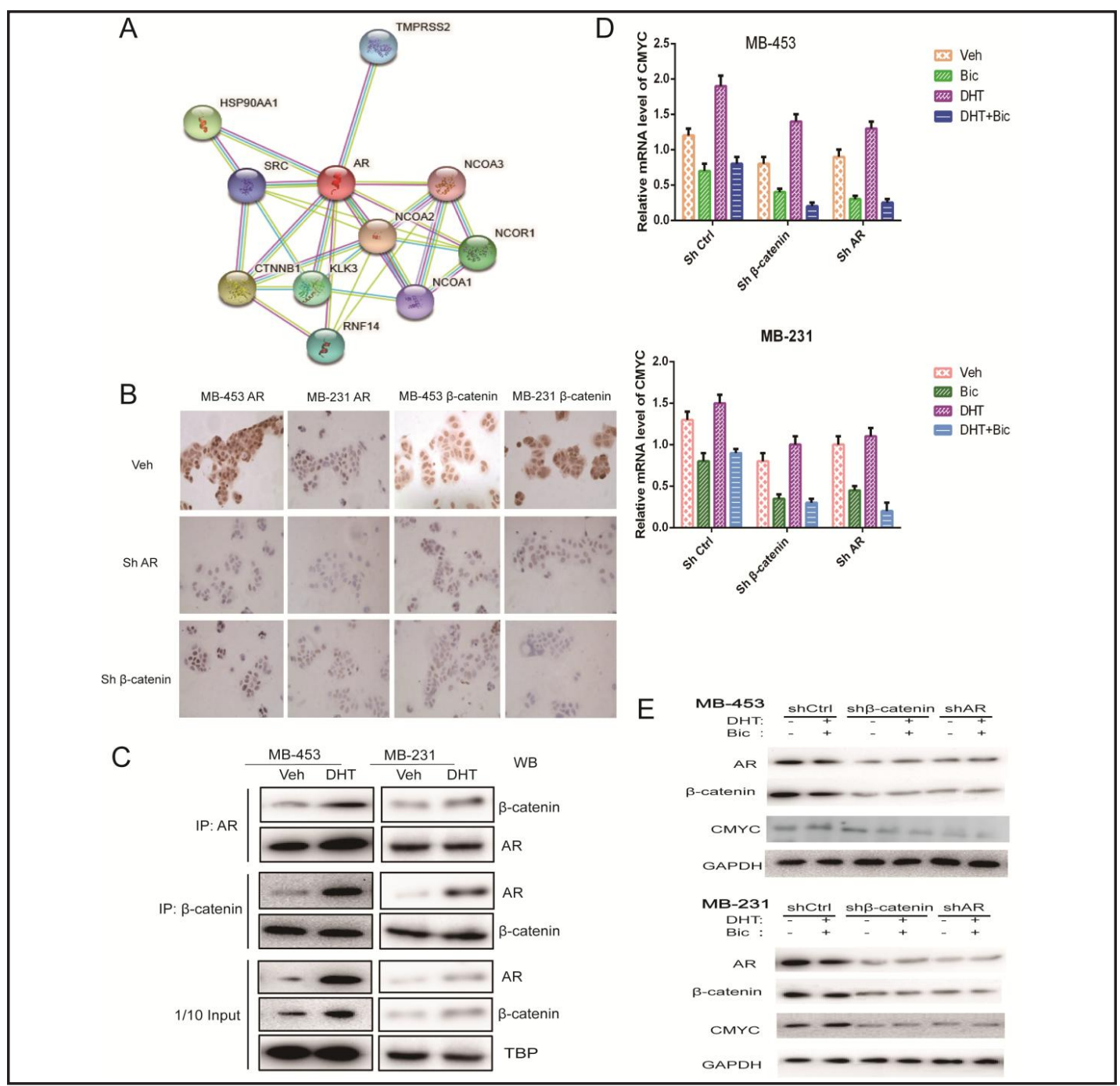

Fig. 6. Bicalutamide (Bic) inhibits $A R$ cooperates with $\beta$-catenin in MB-453 and MB-231 cell lines. (A) Identification of molecular interactions of AR from Ingenuity Pathway Analysis. AR can interact and regulate the function of CTNNB1 ( $\beta$-catenin). (B) AR and $\beta$-catenin knockdown inhibits reciprocal expression by cell histochemistry in MB-453 and MB-231 cell lines. (C) Coimmunoprecipitation of endogenous AR and $\beta$-catenin from the extracts of MB-453 and MB-231 cell lines. (D) MB-453 and MB-231 cells transduced with the indicated shRNA lentivirus were treated with vehicle, Bic, and/or DHT, and the total RNA was subjected to RT-PCR of CMYC. mRNA levels are presented as means with SD. (E) Immunoblotting to determine CMYC expression in MB-453 and MB-231 cells after transduction of the indicated lentiviral shRNA followed by vehicle (-) or DHT and Bic (+) treatment.

that AR can interact with and may regulate the function of many genes, such as CTNNB1 ( $\beta$-catenin), NCOA1-3, SRC, and KLK3. We verified our hypothesis that AR+/ER- breast cancer might depend on the AR and $\beta$-catenin transcription complex and benefits from treatment with bicalutamide. AR silencing caused a decrease in $\beta$-catenin at the protein expression level. Interestingly, $\beta$-catenin knockdown also diminished AR expression, as determined by immunocytochemical analysis of MB-453 and MB-231 cells (Fig. 6B). We detected the interaction between AR and $\beta$-catenin in the extracts of MB-453 and MB-231 breast cancer cells by coimmunoprecipitation (Fig. 6C). We confirmed by RT-PCR that bicalutamide treatment substantially reduced the mRNA expression level of CMYC and that the silencing of $\beta$-catenin and AR effectively impeded the expression of CMYC (Fig. 6D). Bicalutamide KARGER 
Huang et al:: AR Expression and Bic Antagonize AR Inhibit $\beta$-Catenin in ER- Breast Cancer

Fig. 7. Model of AR antagonism role of bicalutamide (Bic) in inhibiting Wnt/ $\beta$-catenin in ER-negative breast cancer. Bic target AR and indirect suppression transcription complex $\mathrm{AR}$ and $\beta$-catenin by Wnt/ $\beta$ catenin pathway. (A) Before Bic. (B) After applying Bic.

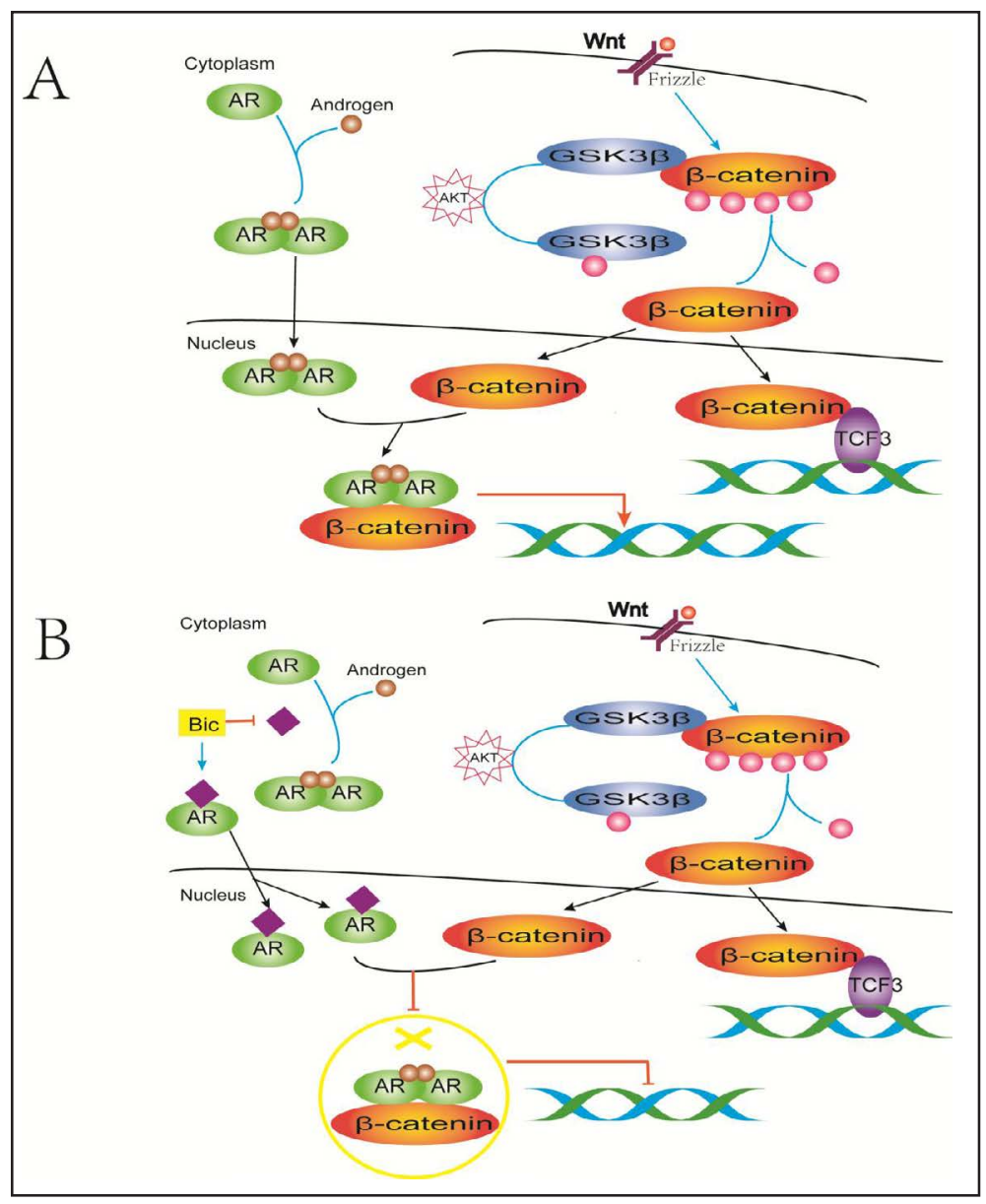

inhibition led to a reduced expression of CMYC, which was also observed with AR or $\beta$-catenin silencing. As expected, the Western blot assay suggested that knockdown of AR diminished $\beta$-catenin expression; interestingly, $\beta$-catenin silencing caused a decrease in the AR protein expression level, and knockdown of AR or $\beta$-catenin inhibited CMYC expression in MB-453 and MB-231 cells (Fig. 6E). In short, these results demonstrate that inhibiting AR with bicalutamide blocks androgen-stimulated oncogenic Wnt/ $\beta$-catenin signaling and inhibits the growth of ER-/AR+ breast tumors.

\section{Discussion}

Endocrine therapies that target ER and estrogen signaling pathways play a crucial role in the treatment of the majority of breast cancer patients. However, over a quarter of breast cancers fail to express ER, and ER-negative patients are not suitable for these endocrine therapies. Our findings show that a considerable number of ER-negative breast cancers express AR and that their growth is stimulated by androgens. We have suggested that AR+/ ER- breast cancer might critically depend on the AR and $\beta$-catenin transcription complex and may benefit from treatment with bicalutamide.Our study found that bicalutamide antagonizes AR to inhibit oncogenic Wnt/ $\beta$-catenin signaling pathways through the transcriptional down regulation of CMYC in AR+/ER- breast cancer (as summarized in Fig. 7). This regulatory network indicates a reciprocal link between AR and Wnt/ $\beta$-catenin pathways in ER-negative breast cancer. Although the existence of AR in breast cancer has been studied for decades, it has not been widely investigated as a potential therapeutic target in malignant breast neoplasms [28].

\section{KARGER}




\section{Cellular Physiology Cell Physiol Biochem 2017;43:2212-2225

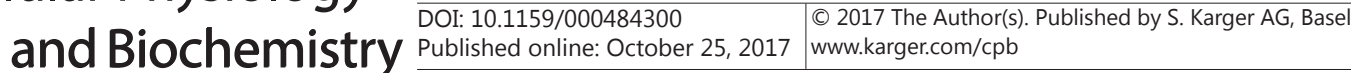 \\ Huang et al.: AR Expression and Bic Antagonize AR Inhibit $\beta$-Catenin in ER- Breast Cancer}

TNBC and Her2 overexpression breast cancers are biologically more aggressive, are associated with a higher recurrence rate during the first 1-3 years and have a significantly worse overall survival $[7,32,33]$.The poor prognosis of patients with TNBC is due to a lack of effective endocrine and targeted therapy. However, AR is expressed in up to 30$50 \%$ of patients with TNBC and represents an opportunity for endocrine and targeted therapy [27, 34-36]. Our studies showed that the expression levels of AR in TNBC and Her2 overexpression similar to the results of several other studies [5-7, 12, 15, 32-36]. This range concurs with the rate of AR expression of 39\% and $76 \%$ achieved in our triple-negative and Her2 overexpression series [4, 15, 33-35]. Our results reported that ER-negative tumors with AR expression has are associated with significantly better disease-free survival than AR-negative tumors [12, 14, 15, 32-36]. It was postulated by Doane [37] that AR functions as an antiproliferative effector in ER-positive breast cancer by antagonizing ER, whereas it facilitates tumor cell proliferation and growth in an androgen-dependent manner in ER-/ $\mathrm{AR}+$ breast cancer. Identifying the underlying mechanisms of AR is crucial for designing therapies for estrogen-insensitive neoplasms.

Steroid hormone receptors are crucial components of signaling pathways and act as transcription factors to regulate gene expression [38]. Along with their coactivators, these transcription factors play an important role in breast cancer oncogenesis and progression. AR has been implicated in breast tumorigenesis. However, delineating its precise function has proven difficult. Our study demonstrated that bicalutamide decreases proliferation and increases apoptosis in vitro. Moreover, the effects of bicalutamide on viability and apoptosis through AR inhibition in vivo were recapitulated in MB-453 and MB-231 xenografts in nude mice. Bicalutamide inhibits cell proliferation and induces apoptosis in AR-positive mesenchymal stem-like TNBC cell lines increasing the expression of p73 and p21 and negatively regulating p53 and Cyclin D1 [39]. Several studies have focused on the role of the high AR-expressing molecular subtype in TNBC and have found that this subtype is responsive to bicalutamide, whereas this subtype is less responsive or nonresponsive to enzalutamide [7, 40].

Our work indicates that targeting AR with antagonists such as bicalutamide may be another way to target the Wnt/ $\beta$-catenin signaling pathway. A role for Wnt signaling in primary breast cancers of the ER-negative subtype has been described $[19,41]$. A phase II clinical trial of bicalutamide in AR+/ER- metastatic breast cancer reported a 19\% clinical benefit rate and a median increase of 12 weeks in progression-free survival [3]. In addition, a phase II clinical trial is currently testing the efficacy of enzalutamide in AR+ TNBC (NCT01889238). Bartonreported that MB-231 cells were less sensitive to enzalutamide, as determined by soft agar and caspase-3/7 assays. In our studies, we have shown that the AR level is significantly associated with disease outcome, and our results indicate that the biological functions of bicalutamide decrease proliferation and increase apoptosis in AR+/ER- subtype of breast cancer cells in vitro and vivo. The discrepancy in results may be due to differences in the mechanisms of action of the two AR antagonists. Bicalutamide permits AR nuclear localization and binding to chromatin, recruiting corepressors rather than coactivators, whereas enzalutamide inhibits nuclear localization and DNA binding [42].

The direct effect of AR on the Wnt/ $\beta$-catenin expression level was previously unknown in normal mammary glands and breast tumors. We found that the interaction between $\beta$-catenin and AR formed a transcription complex to regulate the downstream gene of the Wnt/ $\beta$-catenin pathway: CMYC. This regulatory network indicated an intrinsic link between $\mathrm{AR}$ and the Wnt/ $\beta$-catenin pathway in AR+/ER- breast cancer. These results demonstrated that bicalutamide blocks androgen-stimulated oncogenic AR and Wnt/ $\beta$-catenin signaling and inhibits the growth of AR+/ER- breast cancer.

Although our study generates some important findings, it also has some limitations. Our population is too small and limited to completely determine the prognostic outcomes of different regions and races. Therefore, more multi-ethnic cases and longer follow-up periods may be necessary for this type of analysis. In addition, more studies examining the 


\section{Cellular Physiology Cell Physiol Biochem 2017;43:2212-2225

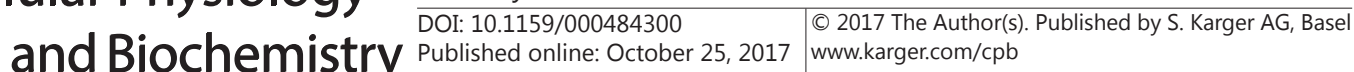

Huang et al.: AR Expression and Bic Antagonize AR Inhibit $\beta$-Catenin in ER- Breast Cancer

mechanism of other cell lines and pathways are needed. Much remains to be done, and more accurate data need to be generated in order to yield more valuable findings in the future.

In conclusion, our study not only provides novel insights into the antagonism of bicalutamide on AR function in AR+/ER- breast cancer but also reveals the mechanistic basis for targeting $A R$ as a therapeutic opportunity for patients with AR+/ER- breast tumors.

\section{Acknowledgments}

This work was supported by grants from National Natural Science Foundation of China (No. 81302286 to YNS), China Postdoctoral Science Foundation (No. 2016M590209 to YNS), Heilongjiang Natural Science Foundation of China (No. H2015050 to YNS), Heilongjiang Province scientific research project Fund (No. 201704 to YNS), State Administration Foreign Experts Affairs China (No. P172011026 to YNS), Heilongjiang Province Scientific Research Project Fund (No. 201504 to RH) and Research Fund of The Second Affiliated Hospital of Harbin Medical University (No. KYBS2015-30 to RH).

\section{Disclosure Statement}

The authors declare no conflicts of interests.

\section{References}

1 Gene Expression data for AR extracted from CCLE_Expression_Entrez_2012-10-18 res: Gene-centric RMAnormalized mRNA expression data.

2 Park S, Koo JS, Kim MS, Park HS, Lee JS, Lee JS, Kim S I, Park B W, Lee K S: Androgen receptor expression is significantly associated with better outcomes in estrogen receptor-positive breast cancers. Ann Oncol 2011;22:1755-1762.

- 3 Gucalp A, Tolaney S, Isakoff SJ, Ingle JN, Liu MC, Carey LA, Blackwell K, Rugo H, Nabell L, Forero A, Stearns V, Doane AS, Danso M, Moynahan ME, Momen LF, Gonzalez JM, Akhtar A, Giri DD, Patil S, Feigin KN, Hudis CA, Traina TA: Phase II trial of bicalutamide in patients with androgen receptor-positive, estrogen receptornegative metastatic Breast Cancer. Clin Cancer Res 2013;19:5505-5512.

4 Peters AA, Buchanan G, Ricciardelli C, Bianco-Miotto T, Centenera MM, Harris JM, Jindal S, Segara D, Jia L, Moore NL, Henshall SM, Birrell SN, Coetzee GA, Sutherland RL, Butler LM, Tilley WD: Androgen receptor inhibits estrogen receptor-alpha activity and is prognostic in breast cancer. Cancer Res 2009;69:61316140 .

5 Vera-Badillo FE, Templeton AJ, de Gouveia P, Diaz-Padilla I, Bedard PL, Al-Mubarak M, Seruga B, Tannock IF, Ocana A, Amir E: Androgen receptor expression and outcomes in early breast cancer: a systematic review and meta-analysis. J Natl Cancer I 2014;106:djt319.

6 Qu Q, Mao Y, Fei XC, Shen KW: The impact of androgen receptor expression on breast cancer survival: a retrospective study and meta-analysis. PloS one. 2013;8:e82650.

7 Barton VN, D’Amato NC, Gordon MA, Lind HT, Spoelstra NS, Babbs BL, Heinz RE, Elias A, Jedlicka P, Jacobsen $\mathrm{BM}$, Richer JK: Multiple molecular subtypes of triple-negative breast cancer critically rely on androgen receptor and respond to enzalutamide in vivo. Mol Cancer Ther 2015;14:769-778.

8 Burstein HJ, Prestrud AA, Seidenfeld J, Anderson H, Buchholz TA, Davidson NE, Gelmon KE, Giordano SH, Hudis CA, Malin J, Mamounas EP, Rowden D, Solky AJ, Sowers MR, Stearns V, Winer EP, Somerfield MR, Griggs JJ: American Society of Clinical Oncology clinical practice guideline: update on adjuvant endocrine therapy for women with hormone receptor-positive breast cancer. J Clin Oncol 2010;28:3784-3796.

-9 Jordan VC, Brodie AM: Development and evolution of therapies targeted to the estrogen receptor for the treatment and prevention of breast cancer. Steroids. 2007;72:7-25.

10 Cancer Genome Atlas N: Comprehensive molecular portraits of human breast tumours. Nature. 2012;490:61-70. 


\section{Cellular Physiology Cell Physiol Biochem 2017;43:2212-2225 \begin{tabular}{l|l|l|}
\hline DOI: 10.1159/000484300 & $\begin{array}{l}\text { C) } 2017 \text { The Author(s). Published by S. Karger AG, Basel } \\
\text { www.karger.com/cpb }\end{array}$ \\
\hline
\end{tabular}

Huang et al.: AR Expression and Bic Antagonize AR Inhibit $\beta$-Catenin in ER- Breast Cancer

11 Ahn HJ, Jung SJ, Kim TH, Oh MK, Yoon HK: Differences in Clinical Outcomes between Luminal A and B Type Breast Cancers according to the St. Gallen Consensus 2013 J Breast Cancer. 2015;18:149-59..

12 Niemeier LA, Dabbs DJ, Beriwal S, Striebel JM, Bhargava R: Androgen receptor in breast cancer: expression in estrogen receptor-positive tumors and in estrogen receptor-negative tumors with apocrine differentiation. Modern Pathol 2010;23:205-212.

13 Ni M, Chen Y, Lim E, Wimberly H, Bailey ST, Imai Y, Rimm DL, Liu XS, Brown M: Targeting androgen receptor in estrogen receptor-negative breast cancer. Cancer cell 2011;20:119-131.

14 Micello D, Marando A, Sahnane N, Riva C, Capella C, Sessa F: Androgen receptor is frequently expressed in HER2-positive, ER/PR-negative breast cancers. Virchows Arch 2010;457:467-476.

15 Safarpour D, Tavassoli FA: A targetable androgen receptor-positive breast cancer subtype hidden among the triple-negative cancers. Arch Pathol Lab Med 2015;139:612-617.

16 Memorial Sloan-Kettering Cancer Center and National Cancer Institute (NCI). Bicalutamide in treating patients with metastatic breast cancer. NIH Web site. http://clinicaltrials.gov/ct2/show/NCT00468715.

17 Medivation, Inc and Astellas Pharma Inc. Safety and Efficacy Study of Enzalutamide in Patients With Advanced, Androgen Receptor-Positive, Triple Negative Breast Cancer. NIH Web site. https://clinicaltrials. gov/show/NCT01889238.

18 Higa GM, Fell RG: Sex hormone receptor repertoire in breast cancer. Int J Breast Cancer. 2013;2013:284036.

19 Khramtsov AI, Khramtsova GF, Tretiakova M, Huo D, Olopade OI, Goss KH: Wnt/beta-catenin pathway activation is enriched in basal-like breast cancers and predicts poor outcome. Am J Pathol 2010;176:29112920.

20 Hatsell S, Rowlands T, Hiremath M, Cowin P: Beta-catenin and Tcfs in mammary development and cancer. J Mammary Gland Biol Neoplasia, 2003;8:145-158.

-21 Chesire DR, Isaacs WB: Ligand-dependent inhibition of beta-catenin/TCF signaling by androgen receptor. Oncogene 2002;21:8453-8469.

22 Edge SB, Compton CC: The American Joint Committee on Cancer: the 7th edition of the AJCC cancer staging manual and the future of TNM. Ann Surg Oncol 2010;17:1471-1474.

-23 Song YN, Geng JS, Liu T, Zhong ZB, Liu Y, Xia BS, Ji HF, Li XM, Zhang GQ Ren YL, Li ZG, Pang D: Long CAG repeat sequence and protein expression of androgen receptor considered as prognostic indicators in male breast carcinoma. PloS one 2012;7:e52271.

-24 Huang R, Wang GY, Song YN, Wang F, Zhu B, Tang QC, Liu Z, Chen YG, Zhang Q, Muhammad S, Wang X: Polymorphic CAG Repeat and Protein Expression of Androgen Receptor Gene in Colorectal Cancer. Mol Cancer Ther 2015;14:1066-1074.

25 Hammond ME, Hayes DF, Dowsett M, Allred DC, Hagerty KL, Badve S, Fitzgibbons PL, Francis G, Goldstein NS, Hayes M, Hicks DG, Lester S, Love R, Mangu PB, McShane L, Miller K, Osborne CK, Paik S, Perlmutter J, Rhodes A, Sasano H, Schwartz JN, Sweep FC, Taube S. Torlakovic EE, Valenstein P, Viale G, Visscher D, Wheeler T, Williams RB, Wittliff JL, Wolff, AC: American Society of Clinical Oncology/College Of American Pathologists guideline recommendations for immunohistochemical testing of estrogen and progesterone receptors in breast cancer. J Clin Oncol 2010;28:2784-2795.

-26 Wolff AC, Hammond ME, Hicks DG, Dowsett M, McShane LM, Allison KH, Allred DC, Bartlett JM, Bilous M, Fitzgibbons P, Hanna W, Jenkins RB, Mangu PB, Paik S, Perez EA, Press MF, Spears PA, Vance GH, Viale G, Hayes DF: American Society of Clinical Oncology/College of American Pathologists guideline recommendations for human epidermal growth factor receptor 2 testing in breast cancer. J Clin Oncol 2013;31:3997-4013.

-27 Lyu S, Yu Q Ying G, Wang S, Wang Y, Zhang J, Niu Y: Androgen receptor decreases CMYC and KRAS expression by upregulating let-7a expression in ER-, PR-, AR+ breast cancer. Int J Oncol 2014;44:229-237.

-28 Caiazza F, Murray A, Madden SF, Synnott NC, Ryan EJ, O’Donovan N, Crown J, Duffy MJ: Preclinical evaluation of the AR inhibitor enzalutamide in triple-negative breast cancer cells. Endocr-Relat Cancer 2016;23:323-334.

29 Subik K, Lee JF, Baxter L, Strzepek T, Costello D, Crowley P, Xing L, Hung MC, Bonfiglio T, Hicks DG, Tang P: The Expression Patterns of ER, PR, HER2, CK5/6, EGFR, Ki-67 and AR by Immunohistochemical Analysis in Breast Cancer Cell Lines. Breast cancer 2010;4:35-41.

-30 Recchione C, Venturelli E, Manzari A, Cavalleri A, Martinetti A, Secreto G: Testosterone, dihydrotestosterone and oestradiol levels in postmenopausal breast cancer tissues. J Steroid Biochem Mol Biol 1995;52:541546. 


\section{Cellular Physiology Cell Physiol Biochem 2017;43:2212-2225

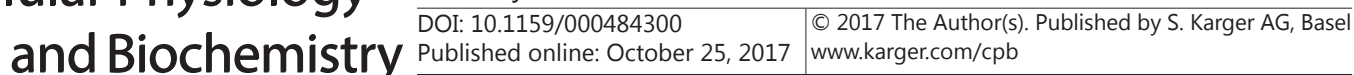

Huang et al.: AR Expression and Bic Antagonize AR Inhibit $\beta$-Catenin in ER- Breast Cancer

31 Sedelaar JP, Isaacs JT: Tissue culture media supplemented with $10 \%$ fetal calf serum contains a castrate level of testosterone. Prostate 2009;69:1724-1729.

32 Yu Q, Niu Y, Liu N, Zhang JZ, Liu TJ, Zhang RJ, Wang SL, Ding XM, Xiao XQ: Expression of androgen receptor in breast cancer and its significance as a prognostic factor. Ann Oncol 2011;22:1288-1294.

33 Ricciardi GR, Adamo B, Ieni A, Licata L, Cardia R, Ferraro G, Franchina T, Tuccari G, Adamo V: Androgen Receptor (AR), E-Cadherin, and Ki-67 as Emerging Targets and Novel Prognostic Markers in TripleNegative Breast Cancer (TNBC) Patients. PloS one 2015;10:e0128368.

-34 Collins LC, Cole KS, Marotti JD, Hu R, Schnitt SJ, Tamimi RM: Androgen receptor expression in breast cancer in relation to molecular phenotype: results from the Nurses' Health Study. Modern Pathol 2011;24:924931.

-35 Mrklic I, Pogorelic Z, Capkun V, Tomic S: Expression of androgen receptors in triple negative breast carcinomas. Acta Histochem 2013;115:344-348.

36 Thike AA, Yong-Zheng Chong L, Cheok PY, Li HH, Wai-Cheong Yip G, Huat Bay B, Tse GM, Iqbal J, Tan, PH: Loss of androgen receptor expression predicts early recurrence in triple-negative and basal-like breast cancer. Modern Pathol 2014;27:352-360.

37 Doane AS, Danso M, Lal P, Donaton M, Zhang L, Hudis C, Gerald WL: An estrogen receptor-negative breast cancer subset characterized by a hormonally regulated transcriptional program and response to androgen. Oncogene 2006;25:3994-4008.

-38 Li S, Han B, Liu G, Li S, Ouellet J, Labrie F, Pelletier G: Immunocytochemical localization of sex steroid hormone receptors in normal human mammary gland. J Histochem Cytoch 2010;58:509-515.

-39 Zhu AY, Li Y, Song W, Xu YM, Yang F, Zhang WW, Yin YM, Guan XX: Antiproliferative effect of androgen receptor inhibition in mesenchymal stem-like triple-negative breast cancer. Cellular Physiology and Biochemistry 2016;38:1003-1014.

-40 Lehmann BD, Bauer JA, Chen X, Sanders ME, Chakravarthy AB, Shyr Y, Pietenpol JA: Identification of human triple-negative breast cancer subtypes and preclinical models for selection of targeted therapies. J Clin Invest 2011;121:2750-2767.

41 Klemm F, Bleckmann A, Siam L, Chuang HN, Rietkotter E, Behme D, Schulz M, Schaffrinski M, Schindler S, Trumper L, Kramer F, Beissbarth T, Stadelmann C, Binder C, Pukrop T: beta-catenin-independent WNT signaling in basal-like breast cancer and brain metastasis. Carcinogenesis 2011;32:434-442.

42 Osguthorpe DJ, Hagler AT: Mechanism of androgen receptor antagonism by bicalutamide in the treatment of prostate cancer. Biochemistry 2011;50:4105-4113. 